\title{
Prevalence and incidence of Mycobacterium tuberculosis infection in nursing students in Vitória, Espírito Santo
}

\author{
Prevalência e incidência de infecção por Mycobacterium tuberculosis \\ em estudantes de enfermagem de Vitória, Espírito Santo
}

\author{
Ethel Leonor Noia Maciel', Maria Carmen Viana², Regina Célia Gomes Zeitoune ${ }^{3}$, \\ Ilce Ferreira ${ }^{1}$, Geisa Fregona ${ }^{1}$ and Reynaldo Dietze $^{1}$
}

\begin{abstract}
This prospective study evaluated the incidence of Mycobacterium tuberculosis infection among nursing students at the Federal University of Espírito Santo, using the purified protein derivative test. In parallel, we evaluated whether knowledge on tuberculosis transmission mechanisms had any impact on nursing students' attitudes in relation to the risk of tuberculosis infection. The incidence of tuberculin conversion was $10.5 \%$ per year $(p=0.035,95 \% \mathrm{CI}=3.63-17.43)$, whereas the expected conversion rate in the overall population in Brazil is 0.5\% per year. These results indicate nursing students as a group at risk for TB infection. Among the risk factors studied only the use of NIOSH95 masks was associated with protection against infection (RR=0.2). Furthermore there was no statistical difference among students that PPD converted and those who remained negative regarding disease knowledge and the existence of adequate facilities for patient hospitalization. Our data reinforces the need for implementing special biosafety programs targeting this professional group.
\end{abstract}

Key-words: Nursing students. Tuberculosis. Purified protein derivative.

\section{RESUMO}

Através de estudo prospectivo, avaliou-se a incidência de infecção pelo Mycobacterium tuberculosis entre estudantes de enfermagem da Universidade Federal do Espírito Santo, usando o teste do derivado de proteína purificado. Paralelamente, avaliamos se o conhecimento sobre mecanismos de transmissão da tuberculose teve algum impacto nas atitudes dos estudantes em relação ao risco de infecção por tuberculose. A incidência da conversão tuberculínica foi de 10,5\% ao ano ( $p=0,035,95 \%$ $C I=3,63-17,43)$, quando a taxa de conversão para a população geral no Brasil é de 0,5\% ao ano. Estes resultados indicam que os estudantes de enfermagem são um grupo de risco para infecção por tuberculose. Dentre os fatores de risco estudados somente o uso da máscara NIOSH95 estava associado à proteção contra a infecção $(R R=0,2)$. Não houve diferença estatisticamente significativa entre os estudantes que converteram o PPD e aqueles que permaneceram negativos em relação ao conhecimento sobre tuberculose e existência de condições específicas para hospitalização dos pacientes com tuberculose. Nossos dados reforçam a necessidade de implementação programas de biosegurança especiais visando este grupo de profissionais.

Palavras-chaves: Estudantes de enfermagem. Tuberculose. Derivado protéico purificado.

Tuberculosis (TB), a disease caused by Mycobacterium tuberculosis $(\mathrm{Mtb})$, is one of the principal causes of mortality in the world today, where one person per second is infected by the bacillus ${ }^{12}$. Mtb infects one-third of the world population, causing approximately 8 million new cases and 3 million deaths per year ${ }^{16}$. In Brazil there are some 90,000 new cases of the disease and more than 5,000 deaths per year $^{16}$. In the State of Espírito Santo, approximately 1,500 cases of the disease and 79 deaths are reported per year.

Geographic distribution of tuberculosis worldwide appears to be related to the countries' socioeconomic conditions. In the majority of the developed countries, the risk of $M$. tuberculosis

\footnotetext{
1. Núcleo de Doenças Infecciosas da Universidade Federal do Espírito Santo, Vitória, ES. 2. Escola de Medicina da Santa Casa de Misericórdia, Vitória, ES. 3. Escola de Enfermagem Ana Nery da Universidade Federal do Rio de Janeiro, RJ.

This work was partially supported by a contract from the National Institutes of Health: AI-45244/AI-95383 (Tuberculosis Research Unit).

Address to: Dra. Ethel Leonor Maciel. Núcleo de Doenças Infecciosas/CBM/UFES. Av. Marechal campos 1468, Maruípe, 29040-091 Vitória, ES.

e-mail: emaciel@ndi.ufes.br

Recebido para publicação em 25/3/2004

Aceito em 26/7/2005
} 
infection is in the order of 0.1 to $0.3 \%$, while in countries with poorer socioeconomic conditions the rate reaches $2.5 \%{ }^{620}$. In Brazil as a whole and in the Southeast Region, where the city of Vitória is located, the risk of $M$. tuberculosis infection is $0.5 \%{ }^{11}$.

From the 1940s through the 60s, when TB was a highly prevalent disease worldwide, several studies already suggested that medical and nursing students were risk groups for infection $^{189}$. However, with the availability of more effective short-duration treatments and the recommendation that treatment no longer be administered in-hospital, nosocomial infection became an issue of only secondary interest. More recently the interest in the subject has reemerged due mainly to the hospitalization of patients with TB-HIV co-infection and the increase in drug resistance by the bacillus ${ }^{45714}$. However, such studies have been performed in countries where the disease prevalence is low, such as the United States and Spain. In Brazil, the infection rate among health professionals is unknown, and the only study published on this matter refers to the prevalence of infection among university students, which in the final analysis serve as markers for the infection ${ }^{18}$. The same study also fails to mention the impact of education on the clinical practice of these professionals.

The current study aimed to evaluate the incidence of $M$. tuberculosis infection in nursing students and the impact of knowledge on protective measures against the disease in relation to nursing students' practice.

\section{PATIENTS AND METHODS}

Volunteer selection/data collection. This was a prospective cohort study conducted from April 1997 to July 1999 with nursing students from the Federal University in Espírito Santo, the only institution in the State offering this course at that time. Of the 223 students enrolled in the nursing course, 178 agreed to participate in the study. The study was divided into two phases. During the first phase (April 1997 to June 1997) all the volunteers were evaluated using an intradermal PPD test (see details below) and a questionnaire with the following information: a) demographic data, including the place of internship/work, b) history of prior contact with TB, c) presence of BCG scar, d) presence of signs and symptoms of TB (cough for more than two weeks, weight loss, fever, and night sweats), and e) knowledge concerning transmission, diagnosis, and treatment of the disease as well as use of preventive measures. We also asked participants if they were afraid of acquiring the disease.

During the second phase of the study, from April to July 1999 , or that is two years after the beginning of the study, all the students with a negative skin test in 1997 were retested with PPD. These results were then compared with the responses to the previously formulated questions in order to verify whether knowledge about the disease and protective measures were determinant factors for PPD conversion.

Intradermal test. The antigen used was PPD Rt23 2TU/0.1ml, obtained from the Brazilian National Tuberculosis Program, which had acquired it from Statens Serum Institute, Copenhagen,
Denmark, and diluted it using standard procedures ${ }^{11}$. After giving informed consent, the volunteers underwent the Mantoux skin test as follows: $0.1 \mathrm{ml}$ of the antigen was administered into the skin on the volar aspect of the left forearm using standard procedures. The same nurse who was trained by the Brazilian National TB Program to read and record the skin test results performed this procedure on all the study subjects. The positive cut-off point for the PPD test was a $10 \mathrm{~mm}$ induration at the 72 hour reading. Any volunteer with a negative result in this evaluation underwent a second test with the same methodology 3 weeks later to rule out a late booster effect ${ }^{1017}$.

Data analysis. The results of the PPD conversion were analyzed, considering the participants' answers to the questionnaire. The statistical test used was Fisher's exact test.

Analysis of the risk of TB infection was calculated using the model proposed by Rufino-Neto ${ }^{15} \boldsymbol{r}=\frac{1}{t} \mathbf{I n} \frac{N o}{N}$; where: $\mathbf{r}=$ risk of infection, No $=$ number of infection-free individuals at baseline, $\mathbf{N}=$ number who remained infection-free after time $\mathrm{t}, \mathbf{t}=$ time transpired between the two PPD tests.

A logistic regression was used to calculate the association between the variables: fear of acquiring infection in subjects with and without a positive PPD skin reaction and the use of masks.

\section{RESULTS}

Thirty-six (20.3\%) out of the 178 students who agreed to participate in the study were PPD positive. Out of these, three students developed signs and symptoms of tuberculosis subsequently confirmed by culture.

Of the 142 PPD-negative students, 39 (27.5\%) were enrolled in the final semester of nursing school and 27 (19\%) were in the penultimate semester, and were thus excluded due insufficient follow-up time. The second phase of the study was conducted with the 76 remaining nursing students available for follow-up (basic undergraduate nursing school lasts 8 semesters in Brazil). Of the 76 students, $87.5 \%$ were females. Age varied from 18 to 35 years. BCG vaccination was $100 \%$, documented by the presence of a vaccine scar in all the participants.

Of the 76 students, 8 (10.5\%) showed PPD conversion, resulting in a $\mathrm{TB}$ infection risk of 2.4 . This risk is approximately 5 times the expected infection risk for the population of Espírito Santo and Brazil as a whole, which is 0.5 . All 8 positive cases were referred for investigation by the TB program. None of these students developed tuberculosis during the study. However, 3 years after concluding the study, one of the students developed pulmonary tuberculosis.

The occupational history of the students showed that those who worked elsewhere (outside the University hospital) presented a 17 times greater risk of PPD-converting compared to those who only studied or did internships at University hospital (HUCAM) (RR=17 p=0.02 CI: 1.7-167.2). In relation to use of protective masks $\left(\right.$ Technol $^{\circledR}$, Inc. PFR95), 37(82.2\%) who reported using masks did not PPD-convert, as compared to only $2(25 \%)$ who showed tuberculin conversion $(\mathrm{RR}=0.3, \mathrm{p}=0.002$ CI:0.09-1.01) (Table 1). 
Table 1- Occupational history of students and PPD status.

\begin{tabular}{|c|c|c|c|c|c|}
\hline \multirow[b]{2}{*}{ Variables } & \multicolumn{2}{|c|}{ PPD-positive } & \multicolumn{2}{|c|}{ PPD-negative } & \multirow[t]{2}{*}{ p-value (CI) } \\
\hline & $\mathrm{f}$ & $\%(n=8)$ & $\mathrm{f}$ & $\%(n=68)$ & \\
\hline Belongs to another professional category & 2 & 25.0 & 4 & 5.9 & 0.2 \\
\hline Works elsewhere(outside University hospital) & 2 & 25.0 & 1 & 1.5 & $0.02^{* * *}$ \\
\hline Contact with TB patient & 8 & 100.0 & 45 & 66.2 & 0.09 \\
\hline \multicolumn{6}{|l|}{ Type of contact* } \\
\hline household & - & 2.0 & 4.44 & 0.99 & \\
\hline hospital & 8 & 100.0 & 3 & 95.5 & \\
\hline \multicolumn{6}{|l|}{ Type of ward where contact occurred } \\
\hline isolation & 2 & 25.0 & 29 & 64.4 & 0.06 \\
\hline ordinary ward & 5 & 62.5 .0 & 28 & 62.2 & 0.99 \\
\hline together with TB patient & 1 & 12.5 .0 & 24 & 53.3 & 0.06 \\
\hline \multicolumn{6}{|l|}{ Facilities in wards } \\
\hline ample windows & 6 & 75.0 & 40 & 88,9 & 0.4 \\
\hline exhaust fan & - & & 17 & 37.8 & \\
\hline PFR95 mask & 2 & 25.0 & 31 & 68.9 & $0.03^{* * \cdots k}$ \\
\hline Surgical mask & 6 & 75.0 & 28 & 62.2 & 0.7 \\
\hline
\end{tabular}

*Based on this variable, an $\mathrm{n}=45$ was computed for the PPD-negative sample.

$* * \mathrm{RR}=17$; CI: $1.7-167.2$

$* * * \mathrm{RR}=0.3$; CI: $0.09-1.01$

In relation to students' knowledge concerning tuberculosis and the existence of adequate facilities for patient hospitalization, there was no statistically significant difference between those with PPD-conversion and those who remained negative (Table 1 and 2). However when we compare the PPD conversion rate in relation to students' fear of acquiring TB, there was a statistically difference among those a positive and negative skin reaction. Only one (12.5\%) out of 8 students with PPD conversion was in the group of students who responded affirmatively to this question. On the other hand, out of the 68 students with a negative PPD, 59 (86.7\%) also responded affirmatively to this question $(R R=0.14$, CI $95 \%=0.02-0.9, p=0.0001)$. The logistic regression

Table 2-Distribution of PPD results based on previous knowledge concerning tuberculosis.

\begin{tabular}{|c|c|c|c|c|c|}
\hline \multirow[t]{2}{*}{ Variable } & \multicolumn{2}{|c|}{ PPD-positive } & \multicolumn{2}{|c|}{ PPD-negative } & \multirow[b]{2}{*}{ p-value } \\
\hline & $\mathrm{f}$ & $\%(\mathrm{n}=8)$ & f & $\%(n=45)$ & \\
\hline \multicolumn{6}{|c|}{ Knows etiological agent } \\
\hline no & 3 & 62.5 & 5 & 11.1 & 0.08 \\
\hline yes & 5 & 37.5 & 40 & 88.9 & \\
\hline \multicolumn{6}{|c|}{ Knows protective measures } \\
\hline no & 1 & 12.5 & 8 & 17.8 & 0.99 \\
\hline yes & 7 & 87.5 & 37 & 82.2 & \\
\hline \multicolumn{6}{|c|}{ Knows clinical signs and symptoms } \\
\hline no & 2 & 25 & 12 & 26.7 & 0.99 \\
\hline yes & 6 & 75 & 33 & 73.3 & \\
\hline \multicolumn{6}{|c|}{ Knows transmission mechanism } \\
\hline no & 1 & 12.57 & 7 & 15.6 & 0.99 \\
\hline yes & 87.5 & 38 & 84.4 & & \\
\hline \multicolumn{6}{|c|}{ Knows diagnosis } \\
\hline no & 3 & 62.5 & 6 & 13.3 & 0.12 \\
\hline yes & 5 & 37.5 & 39 & 86.7 & \\
\hline \multicolumn{6}{|c|}{ Knows treatment } \\
\hline no & 3 & 62.5 & 8 & 17.8 & 0.33 \\
\hline yes & 5 & 37.5 & & 37 & 82.2 \\
\hline
\end{tabular}

analysis between the fear of acquiring TB in subjects with and without a positive PPD skin reaction and the use of masks also reinforces the above results (Table 3).

Table 3 - Logistic regression considering fear of acquiring TB by PPD outcome and use of mask.

\begin{tabular}{lcccc} 
Model & Variable & OR & $95 \%$ CI & p-value \\
\hline Fear+ ppd outcome+ use of mask & PPD outcome & 0.024 & $0.0009-0.6$ & 0.024 \\
& mask & 116.9 & $9.5-1431.7$ & 0.000
\end{tabular}

\section{DISCUSSION}

Our study site, a University Hospital, is a referral center in the State of Espírito Santo for TB patients. During the study period there was an average of 123 hospitalizations/year due to tuberculosis. Among the study volunteers, the prevalence of PPD reactivity was $20.3 \%$, the incidence was $10.5 \%$, and the risk of TB infection was 2.4. These results reinforce the data from the literature indicating that health profession students are a high-risk group for acquiring TB infection and emphasize the importance of occupational exposure during professional training ${ }^{4913}$. One of the risk factors for tuberculin conversion $(\mathrm{RR}=17)$ in this study was another concurrent professional activity besides studying. In Brazil there are three different nursing classes: auxiliary nursing (with only primary schooling), nursing technicians (with a high school diploma), and registered nurses (with a Bachelor of Science degree). The two nursing students with a converted PPD, were also nursing technicians who worked outside the University hospital throughout their undergraduate training.

Prior BCG vaccination, confirmed by the presence of a vaccine scar, is important for interpreting PPD skin test results. Studies have demonstrated that individuals vaccinated during childhood and tested at an interval greater than or equal to 5 years have a tuberculin reactivity pattern similar to the reference population to which they belong ${ }^{1021}$. In other 
words, BCG vaccination in childhood does not interfere with PPD results in adulthood. In our study, the prevalence of a positive tuberculin test in nursing students was $20.3 \%$, far higher than that found in students from other university courses, e.g. economics, where the highest prevalence found was $8.6 \%$ (unpublished data).

Contact with a positive sputum smear patient is the principal risk factor for PPD conversion ${ }^{12}$. This risk can be aggravated by the lack of protective measures, as reported by students who PPD-converted.

Hospitalization of patients in wards with isolation rooms was an important protective factor against TB, clearly confirming the recommendations in the U.S. guidelines and more recently the Brazilian guidelines $^{2}{ }^{19}$. In our hospital only two rooms have negative air pressure. Out of 68 PPD-negative students only $17(37 \%)$ took care of patients in isolation rooms with negative pressure (exhaust fan). None of the students with a converted PPD had access to this facility. In our study, another factor associated with protection against infection was the use of an adequate biosafety mask ( $70 \%$ protection). In fact, because the use of mask is a practical and low-cost measure, it should be adopted routinely by all hospitals in Brazil that treat tuberculosis. This recommendation could decrease transmission in a setting where the public heath system can not afford to provide appropriate wards.

In our study, TB knowledge among nursing students was not a decisive factor in decreasing the risk of infection, measured by PPD conversion. However, fear of acquiring the disease was an important protective factor against PPD conversion. This protection might be related to greater care in patient management and greater compliance to protective measures. Multivariate analysis confirmed this finding, were the fear of acquiring TB had a protective impact on the PPD conversion rate and also a positive impact on the behavior of the students' care with TB patients. Our data also suggest that the incidence of TB infection among nursing students in our setting, a high-incidence country, does not differ from the one found in Spain, a low-incidence country, before biosafety measures implementation ${ }^{4}$. This reinforces the importance of biosafety measures for diseases such as tuberculosis, in order to avoid nosocomial transmission.

\section{REFERENCES}

1. Abruzzi WA, Hummel RJ. Tuberculosis: Incidence among American medical students, prevention and control and the use of BCG. New England Journal of Medicine 248:722-729, 1953.

2. Centers for Disease Control. Guidelines for preventing the transmission of M. tuberculosis in health care facilities. Morbidity and Mortality Weekly Report 43 (nº. RR-13):1-131, 1994
3. Ellner JJ, Hinman AR, Dooley SW, Fischl MA, Sepkowitz KA, Goldberger MJ, Shinnick TM, Iseman MD, Jacobs Jr WR. Tuberculosis Symposium: Emerging Problems and Promise. The Journal of Infectious Diseases 168:537-551, 1993.

4. Esteban J, Gadea I, Fernandez-Roblas R, Granizo JJ, Soriano F. Tuberculous infection in student nurses in Madrid, Spain. International Journal of Tuberculosis and Lung Disease 5: 583-584, 2001.

5. Klitzman S, Kellner P. Control of tuberculosis in the workplace: toward integration of occupational health and public health. Occupational Medicine: State-of-the-Art Reviews 9:723-735, 1994.

6. Kochi A. The global tuberculosis situation and the new control strategy of the World Health Organization. Tubercle 72:1-6, 1991.

7. Laforce FM. The control of infections in hospitals. Prevention and Control of Nosocomial Transmission 1: 4-17, 1997.

8. Mcgowan Jr JE. Nosocomial Tuberculosis: New progress in Control and Prevention. Clinical Infectious Diseases 21:489-505, 1995.

9. Meade GM. The prevention of primary tuberculous infections in medical students. The American Review of Tuberculosis 58:675-683, 1948.

10. Menzies D. Interpretation of Repeated Tuberculin Tests. Boosting, Conversion, and Reversion. American Journal of Respiratory Critical Care Medicine 159:15-21, 1999.

11. Ministério da Saúde. Controle da Tuberculose: uma Proposta de Integração Ensino-Serviço. 4⿳⺈-e edição, 1994.

12. Ministério da Saúde. Manual de Normas para o Controle da Tuberculose Centro Nacional de Epidemiologia. Coordenação de Pneumologia Sanitária. 4 a edição, 1995.

13. Myers JA, Boynton RE, Kernan P, Cowan D, Jablon S. Sensitivity to tuberculin among students at the University of Minnesota. The American Review of Tuberculosis 75:442-460, 1957.

14. Pearson ML, Jereb JA, Frieden TR, Crawford JT, Davis BJ, Dooley SW, Jarvis WR. Nosocomial transmission of multidrug-resistant Mycobacterium tuberculosis. Annals of Internal Medicine 117:191-196, 1992.

15. Ruffino-Netto A. Modelos epidemiométricos em tuberculose- definição de "estados" e risco de infecção. Revista de Saúde Pública 11:188-198, 1977.

16. Sepkowitz KA. AIDS, Tuberculosis, and Health Care Workers. Clinical Infectious Diseases 20: 232-242, 1995.

17. Sepulveda R, Ferrer X, Latrach C, Soresen R. The Influence of CalmetteGuerin Bacillus Immunization on the Booster Effect of Tuberculin Testing in Healthy Young Adults. American Review of Respiratory Disease 142:2428, 1990.

18. Silva VM, Cunha AJ, Oliveira JR, Figueira MM, Nunes ZB, DeRiemer K, Kritski AL. Medical students at risk of nosocomial transmission of Mycobacterium tuberculosis. International Journal of Tuberculosis and Lung Disease 4:420-426, 2000.

19. Sociedade Brasileira de Pneumologia. I Consenso Brasileiro de Tuberculose. Biossegurança e Isolamento Respiratório em Tuberculose. Jornal de Pneumologia 23:339-341, 1997.

20. Sokolove PE, Mackey D Wiles J, Lewis RJ. Exposure of emergency department personnel to tuberculosis: PPD testing during an epidemic in the community. American College of Emergency Physicians 24:418-421, 1994.

21. Teixeira L, Maciel E, Dutra ME, Perkins MD, Johnson JL, Dettoni VV. Simultaneous comparison of reactivity to purified protein derivative TR23 and Tubersol in health care workers in Vitória, Brazil. International Journal of Tuberculosis and Lung Disease 4:1074-1077, 2000.

22. Zaza S, Blumberg HM, Beck-Sague C, Haas WH, Woodley CL, Pineda M, Parrish C, Crawford JT, McGowan Jr JR, Jarvis WR. Nosocomial Transmission of Mycobacterium tuberculosis: Role of Health Care Workers in Outbreak Propagation. The Journal of Infectious Diseases 172:1542-1549, 1995. 